\title{
Assessment of Organ Dose by Direct and Indirect Measurements for a Wide Bore X-Ray Computed Tomography Unit That Used in Radiotherapy*
}

\author{
Emine Dilek Cakmak¹, Nina Tuncel1,2\#, Bora Sindir² \\ ${ }^{1}$ Department of Physics, Faculty of Science, Akdeniz University, Antalya, Turkey \\ ${ }^{2}$ Department of Radiation Oncology, Faculty of Medicine, Akdeniz University, Antalya, Turkey \\ Email: "ninatuncel@gmail.com
}

Received 7 March 2015; accepted 7 April 2015; published 13 April 2015

Copyright (C) 2015 by authors and Scientific Research Publishing Inc.

This work is licensed under the Creative Commons Attribution International License (CC BY). http://creativecommons.org/licenses/by/4.0/

(c) (i) Open Access

\section{Abstract}

The aim of this study was to investigate the organ doses of patients undergoing computed tomography (CT) examination using the wide bore General Electric (GE) "Light Speed RT" unit. The head, chest and pelvic regions of the Rando-phantom were scanned with $120 \mathrm{kV}, 200 \mathrm{~mA}$, and 2.5 mm slice thickness for helical and axial modes. Thermoluminescent Dosimeter (TLD) pairs were used for the dosimetry of 10 organs. TL-counts were converted to dose by using CTDI CT-phantom. For the calculation of the organ doses, the ImPACT software was utilized by entering CTDI $_{\text {air }}(100 \mathrm{mAs})$ in small and large field of view (26.43 and $21.17 \mathrm{mGy}$ respectively). The in-field dose ranges in helical and axial modes were 64.3 - 38 mGy and 47.6 - $19.7 \mathrm{mGy}$ in head, 48.3 - 14.1 mGy and 34.1 - 10 mGy in chest, 28.4 - 10.2 mGy and 21 - $8.5 \mathrm{mGy}$ in pelvic, respectively. The organ doses from software and TLD were compared and tailored as the in-field and the out-field radiation. First results showed that the organ dose was relatively higher in the helical mode on both direct and indirect measurement. The in-field organ dose differences between TLD and software were seen. In helical and axial modes, the dose differences ranged from +1 to +13.3 and -8.3 to $+9.6 \mathrm{mGy}$ for head exam, +1.1 to $+\mathbf{1 5 . 3}$ and +0.3 to $+9.1 \mathrm{mGy}$ for chest, and -21.7 to +1.9 and -15.5 to $+1.8 \mathrm{mGy}$ for pelvic. The availability of this program for organ dose calculations by measuring CTDI $_{\text {air }}$ value for CT device used in the radiotherapy would be considered valuable.

\section{Keywords}

Wide Bore Computed Tomography (CT), Thermoluminescent Dosimeter (TLD), Organ Dose

\footnotetext{
${ }^{*}$ Organ dose in wide bore CT.

"Corresponding author.
}

How to cite this paper: Cakmak, E.D., Tuncel, N. and Sindir, B. (2015) Assessment of Organ Dose by Direct and Indirect Measurements for a Wide Bore X-Ray Computed Tomography Unit That Used in Radiotherapy. International Journal of Medical Physics, Clinical Engineering and Radiation Oncology, 4, 132-142. http://dx.doi.org/10.4236/ijmpcero.2015.42017 


\section{Introduction}

Over the past few decades, technological advances in X-ray computed tomography (CT) technology have made these devices as an essential medical imaging tool in the diagnosis and treatment process.

Until the late 1990s, imaging for radiotherapy was confined to the acquisition of a CT study for treatment planning [1]. Currently, the clinics have been equipped with wide bore CT systems for easy patient positioning and for increasing diagnostic anatomical coverage resulting in optimized diagnosis and treatment. On the other hand, the open beam CT, which provides large fields enough to cover a significant anatomic range in a single rotation for imagining just before a treatment course widely have been used in practices [2]. Some of these systems utilize dose as possible low, whilst saving the normal tissues [2].

The special requirements of a conventional CT platform can provide either helical or axial scanning modes [2]. Patient doses from CT procedures are relatively higher than doses from other imaging modalities based on ionizing radiation [3]-[6]. From the data published in 2006, the use of CT has increased at a rate of $8 \%-15 \%$ per year for the last 7 - 10 years at United States [7]. In 2006, nearly half of the total medical radiation exposure was from CT [8]. According to the UNSCEAR 2010 report, the usage and exposures of CT scanning accounts for $43 \%$ of the total collective effective dose due to diagnostic medical radiology, while the additive dose coming from radiotherapy CT usage was not included [9].

However, the demands of modern radiotherapy planning are quite different from those 20 years ago. In the current radiation therapy planning, radiation oncologists are required to define the target volume more precisely, not just in two dimensions, but also in three dimensions. Therefore, it has become necessary to visualize anatomy in three dimensions to conform the dose around the target volume to as high as possible, whilst saving the normal tissues [10]. The special requirements of a CT simulator suggest that a dedicated CT scanner should be designed especially to address the requirements of radiotherapy treatment planning [10]. In routine radiotherapy, it provides not only clinical anatomical information for correct structure delineation but also the electron density map necessary for dose calculation. In the treatment planning system (TPS), CT numbers are converted into electron density values by means of a specific scanner calibration curve introduced during TPS commissioning.

On the other hand, patients in cancer surveillance protocols can have up to 40 or more CT scans. The use of CT in a cancer surveillance protocol was used as an example of a paediatric patient who had kidney cancer, with surgery and radiation therapy. The active use of diagnostic CT scans lead to a total of 50 CT scans during a seven year period and it was estimated that the patient received an organ dose of 114 mGy to 872 mGy [11].

The basic principles of radiation protection (justification and optimization of a procedure), "ALARA" as low as reasonable achievable principles and the radiation reference level of examination dose need to be respected [12]. With regard to patient safety, frequent CT examinations performed on the same patient are of particular concern. In all medical processes, tracking the individual patient radiation exposure history from imaging to treatment for cumulative dose assessment has become an important issue [13]-[15].

Several CT-specific dose descriptors have been developed: the Multiple Scan Average Dose (MSAD) descriptor, the Computed Tomography Dose Index (CTDI) and its variations (CTDI100, CTDIw, CTDIvol), and the dose-length product (DLP) [16]. Dose variations in CT are mainly due to different scanner types/manufacture and different scanning protocols $(\mathrm{kVp}, \mathrm{mAs})$, as well as due to variations in the selected length of the region to be scanned, tube rotation speed, helical pitch, collimation, filtration, patient weight and patient size [17] [18].

CT systems having wide beam widths along the $\mathrm{z}$ axis wide enough to cover a significant anatomic range in a single rotation are rapidly proliferating in the clinic. Some of these systems utilize a conventional CT platform and can provide either helical or axial scanning modes involving table translation, and can also provide singleor multiple-rotation acquisitions with a stationary table (i.e., at a fixed z-location) [2].

Radiation dose from CT demonstrates variations within the scan plane along the $\mathrm{z}$ axis. Also, in helical scans, the pitch parameter has a direct influence on patient radiation dose. This is essentially because as pitch increases ( $p>1$ ), the time that any one point in space spends in the x-ray beam is decreased [19].

The most practical way to prospectively determine the radiation dose absorbed by the organs and tissues of the body during a CT examination is measuring by direct or indirect methods. In order to evaluate the dose of a patient by direct method, dose measuring on patient or humanoid phantom by using an ionization chamber or small size devices such as TLDs and OSLs etc. [20]-[27]. The another way to assess organ doses as mentioned above is indirect method through measurement of CT dose indexes (CTDI) and published conventional factors obtained from Monte Carlo simulation and mathematical phantoms [21] [28]-[33]. Generally, the estimation of 
organ doses for CT procedures requires the user to supply $\mathrm{CTDI}_{100}$ air, tube current (mA), tube rotation time(s), and pitch values for running simulation programs [34]. In practice, a CTDI can be measured using a pencil ionization chamber with an active length of $100 \mathrm{~mm}$ so $\mathrm{CTDI}_{100}$ expressed in terms of absorbed dose to air (mGy). Such measurements may be carried out with a dosimeter located free-in-air and parallel with the axis of rotation of the scanner (CTDI ${ }_{100, \text { air }}$ [37].

The simulations account for various scanners and technique factors, including scanner geometry, bowtie filtration, beam collimation, tube potential, and current as well as the CT dose index (CTDI) [35]-[38] and the scan length for a given CT examination [39]. On the other hand the estimates of organ and effective dose require using tissue weighting factors. Since 1977, three different sets of tissue weighting factors that used Monte Carlo (MC) based simulations have been defined in publications by the ICRP (ICRP 26, published in 1977; ICRP 60, in 1991; and ICRP 103, in 2007) [12] [40] [41]. Over time, weighting of specific tissues has also changed. As a result of the changes, the estimates of effective dose for the exact same CT examination can differ substantially depending on which ICRP report was used.

Until now various MC data based programs like ImPACT [42], Org Dose [34], CT-EXPO [43] etc. were produced for calculating patient dose in CT applications. One of the most well-known is ImPACT spreadsheet based on NRPB conversion factors for calculation of organ dose [42]. The suggested weighting factors for estimating effective dose were available based on either ICRP 103 or ICRP 60 in this software. The ImPACT CT dosimetry spreadsheet provides organ doses based on 23 Monte Carlo datasets from National Radiological Protection Board (NRPB)'s SR250 report. This program used a simulated hermaphroditic patient (MIRD-5 phantom) having mathematically modelled organs and tissues (Figure 1). The mathematic phantom was divided from head to mid thigh into 208 axial slabs of $5 \mathrm{~mm}$ thickness [44].

The aim of this study, therefore, was to assess the magnitude of organ doses imparted to patients undergoing examinations on a dedicated CT unit used in radiotherapy planning process. It was performed by using TLDs on humanoid phantom and the ImPACT software. The results of both methods including direct and indirect measurement methods for each CT scanning protocols were analysed. Also, these were compared with the previous outcomes from conventional CT.

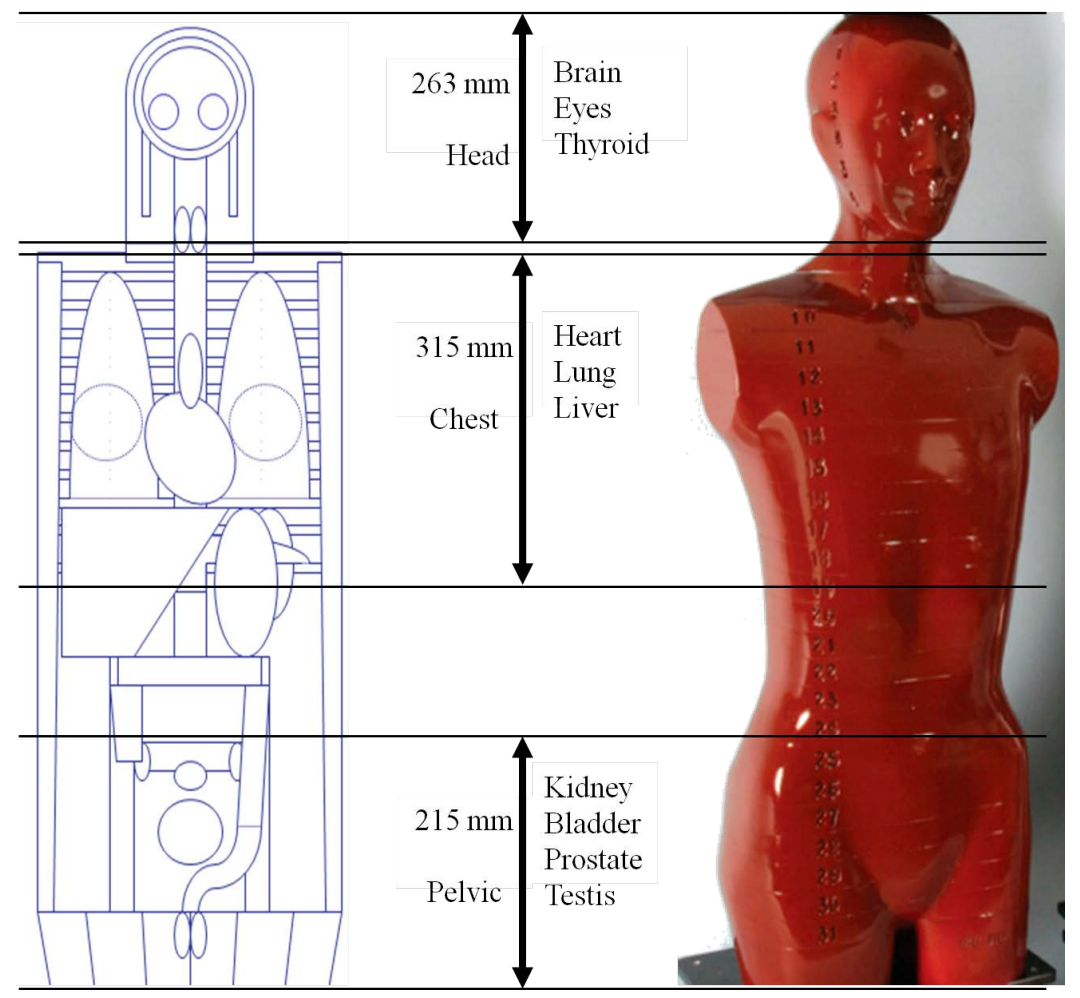

Figure 1. Scan region and its length for each examination were shown on MIRD-5 phantom having mathematically modelled organs and Alderson Rando Phantom. 


\section{Materials and Methods}

GE Light Speed RT, a third generation standard radiotherapy CT (GE Medical Systems, Milwaukee WI), was used in this study. The scanner has a large bore $(80 \mathrm{~cm})$, distance X-ray tube and isocenter $60.6 \mathrm{~cm}$ and performs 4-slice helical scanning. The tube voltage 80 - $140 \mathrm{kV}$ step 20, tube current 10 - $440 \mathrm{~mA}$ step 5, rotation times of 1, 2, 3 and 4 seconds are available. Images were acquired with slice thicknesses of $2.5 \mathrm{~mm}$ on $10.0 \mathrm{~mm}$ collimation $(4 \times 2.5 \mathrm{~mm})($ GE Light Speed RT CT scanner technical evaluation November 2005). This scanner is used routinely for obtaining patient images for radiotherapy treatment planning at the Akdeniz University School of Medicine Department of Radiation Oncology. The regular quality assurance (QA) for image quality, kV-mA measurement and mechanical tests based on national and international processes was performed.

In this study, Alderson Rando phantom (Alderson Research Laboratories, Stanford, USA) was used. This phantom is moulded of tissue-equivalent material; they are designed following highly sophisticated technical constraints and following ICRU-44 standards. Phantom's soft tissue is manufactured from a proprietary urethane formulation with an effective atomic number and mass density that closely simulates muscle tissue with randomly distributed fat. Phantom's lung material closely mimics the density of lungs in a median respiratory state. The molded lungs are hand shaped and fitted to naturally fill the rib cage. The natural human skeletons are used for skeleton construction. The female phantom is $155 \mathrm{~cm}$ tall and $50 \mathrm{~kg}$. The phantom is cut horizontally in to $2.5 \mathrm{~cm}$ thick slices and has 32 slices. Each slice has holes which can be filled with thermoluminescent dosimeters [45].

Three different body regions of the Rando phantom (head, chest and pelvic) were scanned by applying typical clinical protocols. The scan parameters $\mathrm{kV}, \mathrm{mA}$, pitch, FOV (field of view), rotation time, slice thickness of the CT examinations which were used in this study are given in Table 1 . The scan length for each scanning protocol is also shown in Figure 1.

As suggested in direct measurement method, TLDs and humanoid phantom were used for obtaining organ doses.TLD100 type was selected for point dose measurements. Lithium fluoride doped with magnesium and titanium (LiF: Mg, Ti) is manufactured in the form of solid pellets of $4.5 \mathrm{~mm}$ diameter, $0.9 \mathrm{~mm}$ thickness under the code name MTS (MTS-N Poland) [46]. A batch of TLD chips with sensitivity within $\pm 3 \%$ were tested before using. TLDs were calibrated at the energy used in this study. Two TLD chips were placed in a selected hole for each organ; Eye, Brain, Thyroid, Heart, Lungs, Liver, Kidney, Bladder, Prostate, Uterus, and Testis. TLDs were positioned within the phantom, with guidance from a human anatomy CT atlas and clinic experience. Bolus materials were placed on the skin to create dose equilibrium on the eye and the testis. The position of TLDs for various organs within the phantom was shown in Figure 2.

After the exposure of TLDs for each CT examination protocols, the pre-read heating processed was performed $\left(100^{\circ} \mathrm{C}\right.$ for $\left.1 \mathrm{~h}\right)$. The luminescent signals were counted by an automated TLD reader RADOS RE2000RT (RadRro Int. GmbH Germany). Before exposure, the TLDs were annealed at $400^{\circ} \mathrm{C}$ for $1 \mathrm{~h}$ and $100^{\circ} \mathrm{C}$ for 1 h using a PTW high temperature oven (PTW Freiburg GmbH). TLD measurements were done two times for each scanning.

TL-count conversion to dose was done for each scanning parameters using CTDI $_{\text {center }}$ dose measurement on the CT dose phantom.

Table 1. Summary of scan parameters used at dedicated CT scanner for the examination of head, chest and pelvic regions on Alderson Rando phantom.

\begin{tabular}{|c|c|c|c|c|c|c|c|c|}
\hline \multirow{2}{*}{ Region } & \multicolumn{8}{|c|}{ Scan parameters and regions } \\
\hline & Scan mode & $\mathrm{kV}$ & $\mathrm{mA}$ & FOV & Rotation/Sec & Scan length (mm) & Thickness (mm) & Pitch \\
\hline Head & Helical & 120 & 200 & Small & 1 & 263.5 & 2.5 & 0.75 \\
\hline Chest & Helical & 120 & 200 & Large & 1 & 315 & 2.5 & 0.75 \\
\hline Pelvic & Helical & 120 & 200 & Large & 1 & 215 & 2.5 & 0.75 \\
\hline Head & Axial & 120 & 200 & Small & 1 & 257.5 & 2.5 & 1 \\
\hline Chest & Axial & 120 & 200 & Large & 1 & 327.5 & 2.5 & 1 \\
\hline Pelvic & Axial & 120 & 200 & Large & 1 & 217.5 & 2.5 & 1 \\
\hline
\end{tabular}




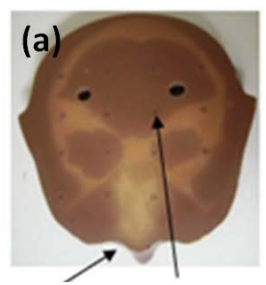

Eye Brain

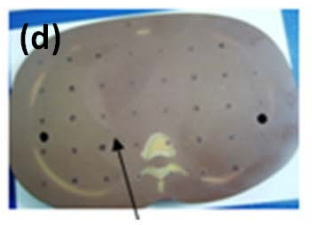

Lung

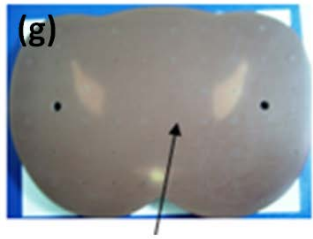

Bladder

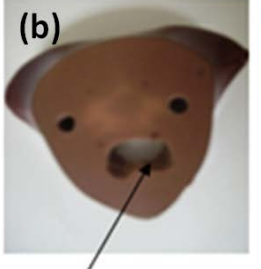

Thyroid

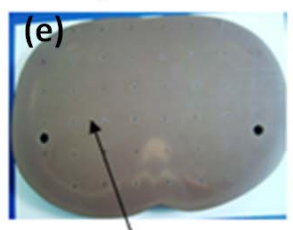

Liver

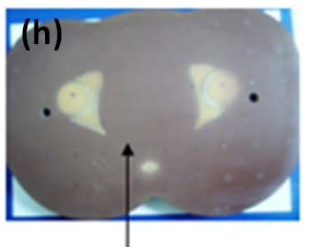

Uterus/ Prostate

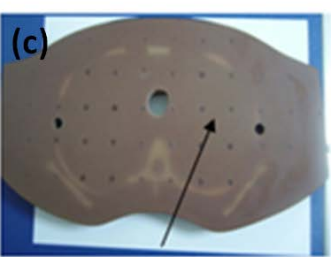

Heart

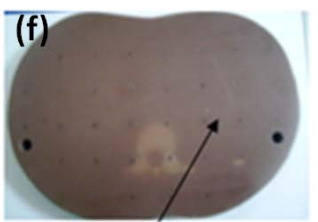

Kidney

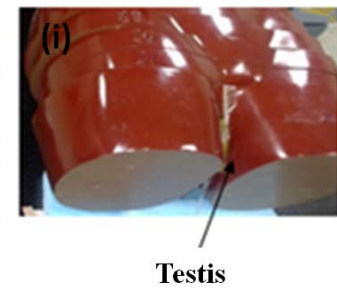

Figure 2. The placements of TLDs in Rando phantom slabs are illustrated. The position of measurement point for organs at each slab was as follow: (a) Eye and Brain; (b) Thyroid; (c) Heart; (d) Lung; (e) Liver; (f) Kidney; (g) Bladder; (h) Uterus/Prostate and (i) Testis.

The Monte Carlo database technique by the ImPACT Group's Excel spreadsheet (version 1.03 24/08/2010) was used for calculating organ doses (Figure 3). The spreadsheet requires the CTDI air $_{\text {as }}$ input measured at 100 mAs. In this study CTDI ${ }_{\text {air }}$ was determined for $120 \mathrm{kVp}, 200 \mathrm{~mA}$, 4 slice with $2.5 \mathrm{~mm}$ thickness, 1 rotation per second, with 1.0 for pitch (axial mode) for small and large FOV (as recommended by GE Medical Systems, Milwaukee WI). The CTDI air was obtained from the measurement of dose along the z-axis made in air at the gantry isocenter using a special pencil shaped $10 \mathrm{~cm}$ length ion chamber with $3.14 \mathrm{cc}$ (TM 30009-0213, PTW-Freiburg) connected to an electrometer (Diados, E type, PTW-Freiburg GmbH) based on selected protocol. The ion chamber which was used in this study was calibrated by manufacturer (PTW-Freiburg GmbH). Then, each CTDI $_{\text {air }}$ value was normalized to $100 \mathrm{mAs}$ for each small and large FOV.

Patient dose estimation for each CT examination using the parameters in Table 1 was carried on by entering $\mathrm{CTDI}_{100}$ value based on FOV. And the list of mean organ dose results was obtained according to organ weighting factors recommended by the ICRP report 103.

The summary of whole process that involved in this study is shown as a flow chart at Figure 4.

\section{Result and Discussion}

The obtained results of CTDI 100 air values for the dedicated GE Light Speed RT CT scanner for small and large FOV were $26.43 \mathrm{mGy}$ and $21.17 \mathrm{mGy}$ respectively. The reported values by manufacturer are $30.16 \mathrm{mGy}$ and 23.9 mGy (GE Report 2005) so ImPACT is used these values as standards at spreadsheet. The obtained results of CTDI 100 air values from this study were less then reported values.

As a general in the literature, the $\mathrm{CTDI}_{100}$ air value for conventional CT scanner is reported to be from 17 to 48 mGy [6] [47]. For this dedicated CT scanner, the CTDI $_{100}$ values were in the range of values from conventional CT.

In this study, the organ dose values were obtained by indirect measurement using the ImPACT calculator and direct measurement using TLDs on the Rando phantom. The two methods were compared for each scan protocol. The organs that were in the scanned region are listed in Table 2. The dose for each organ, the dose difference and the dose ratio of the TLD measurement and the ImPACT calculation values are included. 


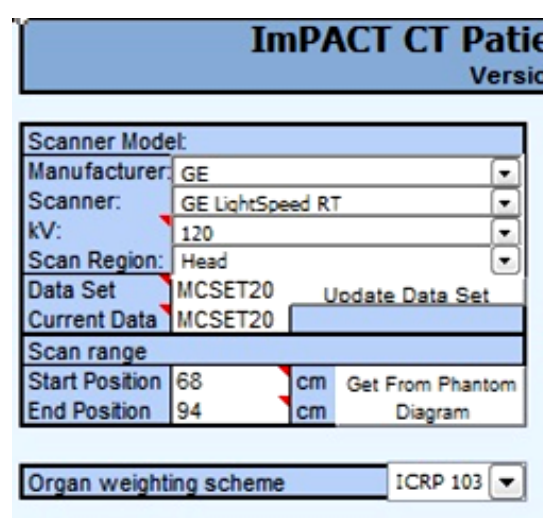

atient Dosimetry Calculator

ersion 1.0.3 24/08/2010

\begin{tabular}{|c|c|c|}
\hline \multicolumn{3}{|c|}{ Acquisition Parameters: } \\
\hline Tube current & 200 & $\mathrm{~mA}$ \\
\hline Rotation time & 1 & s \\
\hline Spiral pitch & 1,33 & \\
\hline mAs / Rotation & 200 & mAs \\
\hline Effective mAs & 150,376 & mAs \\
\hline Collimation & 10 & $-\mathrm{mm}$ \\
\hline Rel. CTDI & 1,00 & at selected collimatio \\
\hline CTDI (air) Look uo & 30,2 & mGy/100mAs \\
\hline CTDI (soft tissue) & 32,3 & $\mathrm{mGy} / 100 \mathrm{mAs}$ \\
\hline Look up & 16,9 & mGy/100mAs \\
\hline $\mathrm{CTDL}_{w}$ & 33,8 & $\mathrm{mGy}$ \\
\hline $\mathrm{CTDh}_{\text {bl }}$ & 25,4 & mGy \\
\hline DLP & 660 & mGy.cm \\
\hline
\end{tabular}

\begin{tabular}{|l|c|c|c|}
\hline Organ & $\mathrm{w}_{\mathrm{T}}$ & $\mathrm{H}_{\mathrm{T}}$ (mGy) & $\mathrm{w}_{\mathrm{T}} \cdot \mathrm{H}_{\mathrm{T}}$ \\
\hline Gonads & 0,08 & 0,000014 & $1,1 \mathrm{E}-06$ \\
Bone Marrow & 0,12 & 2,7 & 0,33 \\
Colon & 0,12 & 0,0017 & 0,0002 \\
Lung & 0,12 & 0,7 & 0,084 \\
Stomach & 0,12 & 0,019 & 0,0023 \\
Bladder & 0,04 & 0,000097 & $3,9 \mathrm{E}-06$ \\
Breast & 0,12 & 0,11 & 0,014 \\
Liver & 0,04 & 0,036 & 0,0015 \\
Oesophagus (Thymus) & 0,04 & 0,58 & 0,023 \\
Thyroid & 0,04 & 33 & 1,3 \\
Skin & 0,01 & 3,7 & 0,037 \\
Bone Surface & 0,01 & 11 & 0,11 \\
Brain & 0,01 & 24 & 0,24 \\
Salivary Glands (Brain) & 0,01 & 24 & 0,24 \\
\hline Remainder & 0,12 & 4,8 & 0,57 \\
Not Applicable & 0 & 0 & 0 \\
\hline \multicolumn{3}{|c|}{ Total Effective Dose (mSv) } & 3 \\
\hline
\end{tabular}

\begin{tabular}{|l|c|}
\hline Remainder Organs & $\mathrm{H}_{\mathrm{T}}$ (mGy) \\
\hline Adrenals & 0,04 \\
Small Intestine & 0,0017 \\
Kidney & 0,0091 \\
Pancreas & 0,03 \\
Spleen & 0,032 \\
Thymus & 0,58 \\
Uterus / Prostate (Bladder) & $9,4 \mathrm{E}-05$ \\
Muscle & 2,2 \\
Gall Bladder & 0,0062 \\
Heart & 0,16 \\
ET region (Thyroid) & 33 \\
Lymph nodes (Muscle) & 2,2 \\
Oral mucosa (Brain) & 24 \\
\hline Other organs of interest & $\mathrm{H}_{\mathrm{T}}$ (mGy) \\
\hline Eye lenses & 29 \\
\hline Testes & 0 \\
Ovaries & $2,7 \mathrm{E}-05$ \\
Uterus & $9,2 \mathrm{E}-05$ \\
Prostate & $9,7 \mathrm{E}-05$ \\
\hline
\end{tabular}

Figure 3. The scan calculation page in the ImPACT Excel spreadsheet (version 1.03).

Table 2. The dose of organs that were in the scanned region is shown for both helical and axial scanning modes.

\begin{tabular}{|c|c|c|c|c|c|c|c|c|c|}
\hline \multicolumn{10}{|c|}{ Scanned Regions and Dose of Organs } \\
\hline \multirow{2}{*}{$\begin{array}{l}\text { Scanned } \\
\text { Region }\end{array}$} & \multirow{2}{*}{ Organ } & \multicolumn{4}{|c|}{ HELICAL } & \multicolumn{4}{|c|}{ AXIAL } \\
\hline & & $\begin{array}{l}\text { ImPACT } \\
\text { (mGy) }\end{array}$ & $\begin{array}{l}\text { TLD } \\
\text { (mGy) }\end{array}$ & \%Diff. & $\begin{array}{c}\text { Ratio } \\
\text { TLD/ImPACT }\end{array}$ & $\begin{array}{l}\text { ImPACT } \\
\text { (mGy) }\end{array}$ & $\begin{array}{l}\text { TLD } \\
\text { (mGy) }\end{array}$ & \%Diff. & $\begin{array}{c}\text { Ratio } \\
\text { TLD/ImPACT }\end{array}$ \\
\hline \multirow{3}{*}{ HEAD } & Eye & 45 & 47.8 & 6 & 1.1 & 33 & 24.8 & -33 & 0.8 \\
\hline & Brain & 37 & 38 & 3 & 1.0 & 28 & 19.7 & -42 & 0.7 \\
\hline & Thyroid & 51 & 64.3 & 21 & 1.3 & 38 & 47.6 & 20 & 1.3 \\
\hline \multirow{3}{*}{ CHEST } & Heart & 33 & 35.7 & 8 & 1.1 & 25 & 34.1 & 27 & 1.4 \\
\hline & Lung & 33 & 48.3 & 32 & 1.5 & 25 & 31.5 & 21 & 1.3 \\
\hline & Liver & 13 & 14.1 & 8 & 1.1 & 9.7 & 10 & 3 & 1.0 \\
\hline \multirow{5}{*}{ PELVIC } & Kidney & 2.9 & 10.2 & 72 & 3.5 & 2.1 & 7.3 & 71 & 3.5 \\
\hline & Bladder & 32 & 28.4 & -13 & 0.9 & 24 & 21 & -14 & 0.9 \\
\hline & Prostate & 32 & 26.9 & -19 & 0.8 & 24 & 20.8 & -15 & 0.9 \\
\hline & Uterus & 25 & 26.9 & 7 & 1.1 & 19 & 20.8 & 9 & 1.1 \\
\hline & Testis & 32 & 10.3 & -211 & 0.3 & 24 & 8.5 & -182 & 0.4 \\
\hline
\end{tabular}




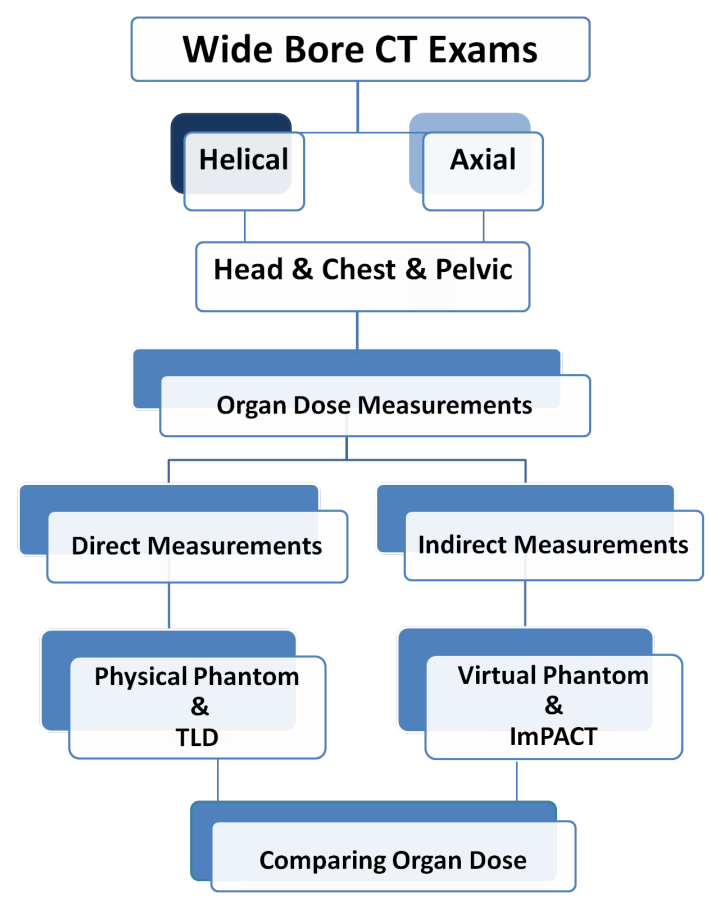

Figure 4. The summery of whole process that involved in this study.

First result of this study showed that the organ dose is relatively higher in helical mode (pitch: 0.75) than axial scanning mode on both direct and indirect dose measurement.

When analyzing by examination type, the best comparable results were obtained for head examination by helical and then by axial one, except thyroid. The thyroid received 1.3 times higher dose, where the measured dose by TLD was 64.3 and $47.6 \mathrm{mGy}$ in helical and axial respectively. The position of TLDs in thyroid on the Rando phantom and the displacement of thyroid in the mathematical phantom would be the reason for the discrepancy. In helical mode, the dose differences for eye, brain and thyroid were 2.8, 1 and 13.3 mGy respectively, while in axial mode, they were $8.2,-8.3$ and $9.6 \mathrm{mGy}$. The dose range to brain in head exams for different conventional scanners was 25.8 - $61 \mathrm{mGy}$, and for eye lens the range was 40.5 - $97.9 \mathrm{mGy}$ [48].

All in-field organ doses measured by the TLDs in the Rando Phantom for chest scanning region were higher than those calculated for both scanning modes. The largest difference was found in the lung about 1.4 times, where the measured dose from the TLD was 48.3 and $31.5 \mathrm{mGy}$ in helical and axial methods, respectively. There is a considerable density difference between the lung and the other organs, so the discrepancy may be based on shape and size of the organs, which were in the scanning region of the mathematical phantom and the Rando phantom. Breiki et al. [48] reported that the range of radiation dose resulted from chest exams which were obtained from conventional scanners was 14.00 - $75.94 \mathrm{mGy}$ for the lung. Comparing to our results from a dedicated scanner it was found that the lung dose was placed on this broad range. Our results were also in this range.

In case of the pelvic exam, the dose of organs measured by the TLDs in the scanned region was slightly lower than the calculated doses in both helical and axial methods. Moreover, about 0.3 and 0.4 times low dose by the TLDs were obtained for testis in helical and axial scanning modes, respectively. The position of the TLDs on the Rando phantom for testis seems more different from mathematical phantom. On the other hand, the largest dose difference obtained by the TLDs was found in the kidney as 3.5 times. In the mathematical phantom, there is a sharp boundary between the abdomen and pelvic organs, like kidney and so on, whereas in the Rando phantom a more realistic distribution of organs was chosen. Simulated scan of the pelvic, therefore, appears to result in a very low dose to the kidney which has a relatively low weighting factor. In practice, however, the selected point for TLD in kidney was in the scanning region and the smaller proportion of the organ on mathematical phantom may be included in the scan volume. The organ dose range values that were driven from conventional scanners for the pelvic exams was 12.77 - 51.43 mGy for uterus, and 3.14 - $15.10 \mathrm{mGy}$ for testis [48]. In general, the or- 
gan dose values from our dedicated scanner were comparable to those values obtained from conventional scanners.

When comparing the measured and the calculated doses for fully irradiated organs the difference between the two methods was attributed to the following factors:

- The difference in the shape and size of the two phantoms.

- The difference in organ positions within the two phantoms.

Generally, for organs laying out of the scanned region the direct dose measurement values by TLD were larger than those calculated by ImPACT. As it has already been observed by other authors [30] [49], experimental dose values were generally larger than those calculated. This happened almost systematically for organs lying out of the scanned region and consequently with low dose values.

In scanning of the head region, the percent dose difference ranged from $63 \%$ to $100 \%$ for both helical and axial scanning modes. The measured dose values by TLD for out-of-field organs based on distance were shown that the higher and lower dose received by heart and testis with $0.7 \mathrm{mGy}$ and $0.07 \mathrm{mGy}$, respectively for helical scanning mode, and the same findings were $0.48 \mathrm{mGy}$ and $0.11 \mathrm{mGy}$ for axial. A discrepancy was determined for lung dose for both scanning modes, the measured and the calculated doses were 0.9 mGy and $1.1 \mathrm{mGy}$ for helical, and $0.52 \mathrm{mGy}$ and $0.81 \mathrm{mGy}$ for axial.

In scanning of the chest region, the out-of-field organ dose difference was ranged between $4 \%-100 \%$ for helical and axial modes. According to TLD measurements; the higher dose received by thyroid was $12.1 \mathrm{mGy}$ and $10.94 \mathrm{mGy}$, whereas the lower dose received by testis was $0.10 \mathrm{mGy}$ and $0.11 \mathrm{mGy}$ for helical and axial modes, respectively.

In scanning of the pelvic region, the out-of-field organ dose difference was ranged between $12 \%$ - $100 \%$ for helical and axial modes. According to TLD measurements; the higher dose received by kidney was 1.04 mGy and $0.70 \mathrm{mGy}$, whereas the lower dose received by eyes was $0.09 \mathrm{mGy}$ and $0.11 \mathrm{mGy}$ for helical and axial modes, respectively.

Struelens and Groves et al. found that the direct dose measuring values were higher than the computer simulated ones which was in agreement with the previously recognized underestimation by computer simulation techniques when compared with TLD measurements [21] [23]. It has already been shown by others [22] that the direct measurements of CT dose in a Rando phantom are up to 40\% higher than the MC technique.

One major cause of the organ dose differences is the distinctions in size and composition between the Rando phantom and conditions considered for mathematical phantoms. This difference is probably due to the differences in the phantoms. The Rando physical phantom has a different size compared with the mathematical phantom of the NRPB and the estimated location of the organs in the Rando phantom as used in this study differs significantly in comparison with the distribution of organs in the mathematical phantom.

Another problem with the MC approach is that the conversion factors are specific to the model of the CT scanners. Calculation of these factors requires data concerning the filtration and collimation of the scanners which may not be available. It should be noted, the dedicated-RT GE scanner that used in this study was up-todate for dose conversion factors [42]. The advantage of the technique described here is that it may be used for any CT scanner and does not require any additional data. In addition, the Rando Alderson phantom has only limited sites drilled for TLD placement. This is not anatomically ideal, especially since there is only one hole drilled for TLD placement in the bone marrow (in the lumbar spine). Nonetheless, as stated above, this phantom has been shown to be a valid tool in dose estimation [50].

\section{Conclusions}

We studied and compared the organ doses from CT examination using the wide bore General Electric (GE) "Light Speed RT" unit in radiation therapy planning experimentally with thermoluminescent detectors in the Rando phantom and also the ImPact software. The input $\mathrm{CTDI}_{100}$ air values were 26.43 and 21.17 mGy in small and large FOV, respectively. The organ doses calculated by ImPACT using a mathematical model of human phantom were lower than the TLD measurement.

The TLD in-field maximum-minimum radiation doses were 64.3 - $38 \mathrm{mGy}$ and 47.6 - $19.7 \mathrm{mGy}$ in helical and axial head scan, respectively. Also, this range was 48.3 - $14.1 \mathrm{mGy}$ and 34.1 - $10 \mathrm{mGy}$ in chest and was 28.4 $10.2 \mathrm{mGy}$ and 21 - $8.5 \mathrm{mGy}$ in pelvic scan. The in-field organ dose differences between the TLD measurements and the ImPACT software were seen. The widest dose difference was obtained in pelvic exam and it was from 
-21.7 to +1.9 mGy and from -15.5 to $+1.8 \mathrm{mGy}$ in helical and axial scan, respectively. In conclusion, direct TLD CT dose measurement has some advantages over indirect computer simulated measurement techniques. However, the TLD measurements are time consuming so it is not very practical and available for routine use in CT imaging procedures. On the other hand, it should be stressed that the CT dose estimations made by simulations according to $\mathrm{CTDI}_{\text {air,100 }}$ would be reliable for application in radiation protection of patients considering the slight underestimations.

All in all, this study will help establishing some reference and guidance dose values for dedicated CT examinations performed at radiotherapy centres, and would allow medical physicists monitor any changes over time that might arise from aging equipment or changing protocols.

\section{Acknowledgements}

This work was supported by Akdeniz University Research Project Coordination Unit (Project No. 2010.02.0121.025).

\section{References}

[1] American Association of Physicists in Medicine (2007) The Management of Imaging Dose during Image-Guided Radiotherapy, Report of the AAPM Task Group 75. Report No. 95. Medical Physicals, 34, 4041-4063.

[2] American Association of Physicists in Medicine (2010) Comprehensive Methodology for the Evaluation of Radiation Dose in X-Ray Computed Tomography, Report of the AAPM Task Group 111. Report No. 111, New York.

[3] United Nations Scientific Committee on Effects of Radiation Atomic Radiation (2000) UNSCEAR 2000 Report Vol. I Sources and Effects of Ionising Radiation Annex D: Medical Radiation Exposures. New York.

[4] International Atomic Energy Agency (2001) Protection of Patients in Diagnostic and Intervention Radiology, Nuclear Medicine and Radiotherapy. Proceeding of International Conference, Malaga, 26-30 March 2001, Austria.

[5] Brenner, D.J., Hall, D., Eric, J. and Phil, D. (2007) Computed Tomography-An Increasing Source of Radiation Exposure. New England Journal of Medicine, 357, 2277-2284. http://dx.doi.org/10.1056/NEJMra072149

[6] Ngaile, J.E. and Peter, K.M. (2006) Estimation of Patient Organ Doses from CT Examinations in Tanzania. Journal of Applied Clinical Medical Physics, 7, 80-94. http://dx.doi.org/10.1120/jacmp.v7i3.2200

[7] National Council on Radiation Protection and Measurements (2009) Ionizing Radiation Exposure of the Population of the United States: Report No.160. Bethesda.

[8] Zhang, Y., Li. X., Segars, W.P. and Samei, E. (2012) Organ Doses, Effective Doses, and Risk Indices in Adult CT: Comparison of Four Types of Reference Phantoms across Different Examination Protocols. Medical Physics, 39, 3404-3423. http://dx.doi.org/10.1118/1.4718710

[9] United Nations Scientific Committee on the Effects of Atomic Radiation (2010) UNSCEAR 2008 Report to the General Assembly Scientific. Volume 1, Annexes A and B, New York.

[10] Aird, E.G.A. and Conway, J. (2002) CT Simulation for Radiotherapy Treatment Planning. British Journal of Radiology, 75, 937-949. http://dx.doi.org/10.1259/bjr.75.900.750937

[11] Lam, D., Wootton-Gorges, S.L., McGahan, J.P., Stern, R. and Boone, J.M. (2011) Abdominal Paediatric Cancer Surveillance Using Serial Computed Tomography: Evaluation of Organ Absorbed Dose and Effective Dose. Seminars in Oncology, 38, 128-135. http://dx.doi.org/10.1053/j.seminoncol.2010.11.009

[12] ICRP International Commission on Radiological Protection (2007) The 2007 Recommendations of the International Commission on Radiological Protection. Publication No. 103, Ann ICRP, 37.

[13] Madan, M.R. and Donald, P.F. (2010) Tracking Radiation Exposure of Patients. The Lancet, 376, 754-755. http://dx.doi.org/10.1016/S0140-6736(10)60657-5

[14] Rehani, M.M. and Donald, P.F. (2011) Patient Exposure Tracking: The IAEA Smart Card Project. Radiation Protection Dosimetry, 147, 314-316. http://dx.doi.org/10.1093/rpd/ncr300

[15] Murphy, M.J., Balter, J., Balter, S., BenComo, J.A., Das, I.J., Jiang, S.B., et al. (2007) The Management of Imaging Dose during Image-Guided Radiotherapy: Report of the AAPM Task Group 75. Medical Physics, 34, 4041-4063. http://dx.doi.org/10.1118/1.2775667

[16] AAPM (1993) Specification and Acceptance Testing of Computed Tomography Scanners. Report of the AAPM Task Group 2, Report No. 39, American Association of Physicists in Medicine, New York.

[17] Kubo, T., Lin, P.J., Stiller, W., Takahashi, M., Kauczor, H.-U., Ohno, Y. and Hatabu, H. (2008) Radiation Dose Reduction in Chest CT: A Review. American Journal of Roentgenology, 190, 335-343. 
http://dx.doi.org/10.2214/AJR.07.2556

[18] Dougeni, E., Faulkner, K. and Panayiotakis, G. (2012) A Review of Patient Dose and Optimisation Methods in Adult and Paediatric CT Scanning. European Journal of Radiology, 81, 665-683. http://dx.doi.org/10.1016/j.ejrad.2011.05.025

[19] McNitt-Gray, M.F., Cagnon, C., Solberg, T.D. and Chetty, I. (1999) Radiation Dose from Spiral CT: The Relative Effects of Collimation and Pitch. Medical Physics, 26, 409-414. http://dx.doi.org/10.1118/1.598532

[20] Harki, E.M.T. and AL-Kinani, A.T. (2007) Measurement of Organ Dose in Chest CT Examination Using Monte Carlo Simulation. Iranian Journal of Radiation Research, 4, 205-209.

[21] Groves, A.M., Owen, K.E., Courtney, H.M., Yates, S.J., Goldstone, K.E., Blake, G.M. and Dixon, A.K. (2004) 16-Detector Multislice CT: Dosimetry Estimation by TLD Measurement Compared with Monte Carlo Simulation. The British Journal of Radiology, 77, 62-65. http://dx.doi.org/10.1259/bjr/48307881

[22] Fearon, F., Xie, H., Cheng. J.Y., Ning, H., Zhuge, Y. and Miller, R.W. (2011) Patient-Specific CT Dosimetry Calculation: A Feasibility Study. Journal of Applied Clinical Medical Physics, 12, 196-209.

[23] Struelens, L., Vanhavere, F. and Smans, K. (2008) Experimental Validation of Monte Carlo Calculations with a Voxelized Rando-Alderson Phantom: A Study on Influence Parameters. Physics in Medicine and Biology, 53, 5831-5844. http://dx.doi.org/10.1088/0031-9155/53/20/018

[24] Mukundan, S., Wang, I.P., Frush, D.P., Yoshizumi, T., Marcus, J., Kloeblen, E. and Moore, M. (2007) MOSFET Dosimetry for Radiation Dose Assessment of Bismuth Shielding of the Eye in Children. American Journal of Roentgenology, 188, 1648-1650. http://dx.doi.org/10.2214/AJR.06.1146

[25] Verhaegen, F., Lemire, M., Hallil, A. and Hegyi, G. (2008) Surface Dosimetry in a CT Scanner Using MOSFET Detectors and Monte Carlo Simulations. Journal of Physics: Conference Series, 102, 1-7. http://dx.doi.org/10.1088/1742-6596/102/1/012026

[26] Hurwitz, L.M., Yoshizumi, T., Reiman, R.E., Goodman, P.C., Paulson, E.K., Frush, D.P., Toncheva, G., Nguyen, G. and Barnes, L. (2006) Radiation Dose to the Fetus from Body MDCT during Early Gestation. American Journal of Roentgenology, 186, 871-876. http://dx.doi.org/10.2214/AJR.04.1915

[27] Jaffe, T.A., Gaca, A.M., Delaney, S., Yoshizumi, T.T., Toncheva, G., Nguyen, G. and Frush, D.P. (2007) Radiation Doses from Small-Bowel Follow-Through and Abdomino Pelvic MDCT in Crohn's Disease. American Journal of Roentgenology, 189, 1015-1022. http://dx.doi.org/10.2214/AJR.07.2427

[28] Hidajat, N., Maurer, J., Schroder, R.J., Nunneman, A., Wolf, M., Pauli, K., et al. (1999) Relationships between Physical Dose Quantities and Patient Dose in CT. The British Journal of Radiology, 72, 556-561. http://dx.doi.org/10.1259/bjr.72.858.10560337

[29] Geleijns, J., Van Unnik, J.G., Zoetelief, J., Zweers, D. and Broerse, J.J. (1994) Comparison of Two Methods for Assessing Patient Dose from Computed Tomography. The British Journal of Radiology, 67, 360-365. http://dx.doi.org/10.1259/0007-1285-67-796-360

[30] Shrimpton, P.C., Jones, D.G., Hillier, M.C., Wall, B.F., Le Heron, J.C. and Faulkner, K. (1991) Survey of CT Practice in the UK. Part 2: Dosimetric Aspects. NRPB-R249, HMSO, London.

[31] Li, X., Samei, E., Segars, W.P., Sturgeon, G.M., Colsher, J.G., Toncheva, G., Yoshizumi, T.T. and Frush, D.P. (2011) Patient-Specific Radiation Dose and Cancer Risk Estimation in CT: Part I. Development and Validation of a Monte Carlo Program. Medical Physics, 38, 397-407. http://dx.doi.org/10.1118/1.3515839

[32] McCollough, C.H., Leng, S., Yu, L., Cody, D.D., Boone, J.M. and McNitt-Gray, M.F. (2011) CT Dose Index and Patient Dose: They Are Not the Same Thing. Radiology, 259, 311-316. http://dx.doi.org/10.1148/radiol.11101800

[33] Demarco, J.J., Cagnon, C.H., Cody, D.D., Stevens, D.M., Mccollough, C.H., O’Daniel, J. and Mcnitt-Gray, M.F. (2005) A Monte Carlo Based Method to Estimate Radiation Dose from Multidetector CT (MDCT): Cylindrical and Anthropomorphic Phantoms. Physics in Medicine and Biology, 50, 3989-4004. http://dx.doi.org/10.1088/0031-9155/50/17/005

[34] Osei, E.K. and Darco, J. (2013) A Survey of Organ Equivalent and Effective Doses from Diagnostic Radiology Procedures. ISRN Radiology, 2013, Article ID: 204346. http://dx.doi.org/10.5402/2013/204346

[35] European Commission (1999) European Guidelines on Quality Criteria for Computed Tomography EUR 16262 EN. Luxemburg Office for Official Publications of the European Communities. http://www.drs.dk/guidelines/ct/quality/Page032.htm

[36] AAPM (2007) The Measurement, Reporting and Management of Radiation Dose in CT: Report of the AAPM Task Group 23. Report No.96, American Association of Physicists in Medicine, New York.

[37] Shope, T.B., Gagne, R.M. and Johnson, G.C. (1981) A Method for Describing the Doses Delivered by Transmission X-Ray Computed Tomography. Medical Physics, 8, 488-495. http://dx.doi.org/10.1118/1.594995 
[38] McCollough, C. (2008) CT Dose: How to Measure, How to Reduce. Health Physics, 95, 508-517. http://dx.doi.org/10.1097/01.HP.0000326343.35884.03

[39] Christner, J.A., Kofler, J.M. and McCollough, J.H. (2010) Estimating Effective Dose for CT Using Dose-Length Product Compared With Using Organ Doses: Consequences of Adopting International Commission on Radiological Protection Publication 103 or Dual-Energy Scanning. American Journal of Roentgenology, 194, 881-889. http://dx.doi.org/10.2214/AJR.09.3462

[40] ICRP International Commission on Radiological Protection (1977) Recommendations of the ICRP. ICRP Publication 26, Ann ICRP, Volume 1.

[41] ICRP International Commission on Radiological Protection (1990) Recommendations of the International Commission on Radiological Protection. ICRP Publication 60, Ann ICRP, Volume 21.

[42] ImPACT Imaging Performance Assessments of CT. CT Patient Dosimetry Spreadsheet (v1.03, 24/08/2010). http://www.impactscan.org/download/ctdosimetrydownload.htm

[43] CT-Expo, Medizinische Hochschule, Hannover, Germany. http://www.mh-hannover.de/fileadmin/kliniken/diagnostische_radiologie/download/ct-expo-e.zip

[44] Jones, D.G. and Shrimpton, P.C. (1991) Survey of CT Practice in the UK. Part 3: Normalised Organ Doses Calculated using Monte Carlo Techniques. NRPB-R250, HMSO, London.

[45] The Alderson Radiation Therapy Phantoms. Radiology Support Devices, Inc. http://www.rsdphantoms.com/rt_art.htm

[46] MIKROLAB s.c. POLAND. http://www.tld.com.pl/tld/mts.htm

[47] Tsapaki, V., Kottou, S. and Papadımitriou, D. (2001) Application of European Commission Reference Dose Levels in CT Examinations in Crete, Greece. The British Journal of Radiology, 74, 836-840. http://dx.doi.org/10.1259/bjr.74.885.740836

[48] Breiki, G., Abbas, Y., El-Ashry, M. and Diyab, H. (2008) Evaluation of Radiation Dose and Image Quality for Patients Undergoing Computed Tomography (CT) Examinations. Proceedings of the IX Radiation Physics \& Protection Conference, Nasr City-Cairo, 15-19 November 2008. http://www.iaea.org/inis/collection/NCLCollectionStore/_Public/40/092/40092043.pdf

[49] Nishizawa, K., Maruyama, T., Takayama, M., Okada, M., Hachiya, J. and Furuya, Y. (1991) Determinations of Organ Doses and Effective Dose Equivalents from Computed Tomographic Examination. The British Journal of Radiology, 64, 20-28. http://dx.doi.org/10.1259/0007-1285-64-757-20

[50] Shrimpton, P.C., Wall, B.F. and Fischer, E.S. (1984) The Tissue Equivalence of the Alderson Rando Anthropomorphic Phantom for X-Rays of Diagnostic Qualities. Physics in Medicine and Biology, 47, 463-467. 